 \\ Педагогические и эргономические условия проектирования персонализированного образовательного пространства
}

\author{
Арно А. О.
}

\begin{abstract}
Аннотация. Цель исследования - определить педагогические и эргономические условия проектирования персонализированного образовательного пространства. В статье раскрывается сущность понятия «персонализированное образовательное пространство», описываются результаты сравнительного анализа подходов к проектированию персонализированного образовательного пространства, обосновывается влияние условий проектирования образовательного пространства на персонализацию процесса обучения. Научная новизна исследования заключается в сравнительном анализе педагогических подходов к проектированию персонализированного образовательного пространства. В результате обоснована необходимость проектирования персонализированного образовательного пространства в соответствии с выделенными условиями: разнообразие и доступность материалов, оборудования, видов активности; снятие поведенческих ограничений и свобода выбора деятельности; возможность взаимодействия с пространством, реализация учащимися пространственного и предметного выбора, изменение своего пространственного окружения; возможность для самовыражения и творческой деятельности; возможность группового взаимодействия и неформального общения; возможность уединения для самостоятельной работы и спокойного отдыха; соответствие возрастным, психофизиологическим и индивидуальным характеристикам учащихся.
\end{abstract}

\section{EN Pedagogical and Ergonomic Conditions for Designing Personalized Educational Space}

Arno A. O.

\begin{abstract}
The aim of the research is to identify pedagogical and ergonomic conditions for designing personalized educational space. The article defines the notion of personalized educational space, describes the results of a comparative analysis of approaches to designing personalized educational space, gives reasons for the influence of conditions for designing educational space on the personalization of the learning process. The scientific originality of the research lies in the comparative analysis of pedagogical approaches to designing personalized educational space. As a result, the study has proved the necessity of designing personalized educational space in accordance with the selected conditions: the variety and availability of materials, equipment, types of activities; the removal of behavioural restrictions and freedom in choosing activities; the ability to interact with the space, the implementation of students' spatial and objective choice, modification of their spatial environment; the opportunities for self-expression and creative work; the opportunities for group interaction and informal communication; the possibility of privacy for individual work and rest; compliance with the students' age, psychophysiological and individual characteristics.
\end{abstract}

\section{Введение}

Актуальность. Согласно концепции «Образование 2030», принятой ЮНЕСКО (Образование преображает жизнь..., 2017), задачами образования сегодня являются: ориентация образовательного процесса на личность учащегося, обеспечение условий для его самореализации; ориентация на активное овладением человеком способов обучения; адаптация образовательных программ к запросам и потребностям личности. Технологии персонализированного обучения позволяют наиболее полно решить задачи, стоящие перед образовательными организациями. Многие ученые (В. В. Грачев (2005), П. Н. Кириллов, Н. И. Корякина (2019), Л. С. Подымова, А. О. Арно (2019)) отмечают, что персонализация обучения базируется на свободном выборе деятельности и культуре совместной работы. При этом важно, насколько образовательное пространство насыщено возможностями для различных видов деятельности и взаимодействия участников образовательного процесса.

Научная статья (original research article) ～～https://doi.org/10.30853/ped210112

(๔ 2021 Авторы. ООО Издательство «Грамота» (๔ 2021 The Authors. GRAMOTA Publishers). Открытый доступ предоставляется на условиях лицензии СС ВY 4.0 (open access article under the CС BY 4.0 license): https://creativecommons.org/licenses/by/4.0/ 
Исследуя проблему создания образовательного пространства, обеспечивающего условия для персонализации обучения, мы пришли к выводу о необходимости введения в педагогическую науку нового понятия, объединяющего основные элементы образовательного пространства и персонализации обучения. Таким понятием, позволяющим дать четкое определение исследуемому явлению, на наш взгляд, является «персонализированное образовательное пространство».

Мы характеризуем персонализированное образовательное пространство как педагогическую реальность, представленную специально организованной совокупностью пространственных элементов, мест взаимодействия субъектов образовательного процесса, направленную на создание условий, способствующих проявлению потенциальных возможностей учащегося, его самопознания и стремления к саморазвитию на основе индивидуальных интересов, потребностей и значимых образовательных целей в соответствии с культурой сотрудничества и сотворчества. В связи с этим возникает вопрос, какие условия должны быть созданы в образовательном пространстве, чтобы оно стало персонализированным?

Для достижения указанной цели исследования необходимо решить следующие задачи:

- выделить условия, способствующие организации персонализированного образовательного пространства, на основе сравнительного анализа педагогических подходов к проектированию персонализированного образовательного пространства;

- охарактеризовать влияние условий проектирования образовательного пространства на персонализацию процесса обучения.

Для решения поставленных задач в статье применяются следующие методы исследования: сравнительносопоставительный метод, системный анализ, метод теоретико-педагогической интерпретации.

Теоретическую базу составили исследования о педагогических подходах к проектированию образовательного пространства (Вербицкий, 1991; Гарднер, 2007; Луминен, Римпеля, Тарвайнен, 2018; Монтессори, 2005; Ясвин, 2019; Kivunja, 2014; Creativity \& innovation..., 2016; Soulé, Warrick, 2015; Thomas, Brown, 2011).

Практическая значимость исследования заключается в возможности использования выделенных условий проектирования персонализированного образовательного пространства при строительстве новых школ и реконструкции существующих зданий образовательных организаций.

\section{Условия, способствующие организации персонализированного образовательного пространства}

В педагогической науке существуют концепции личностно-ориентированного обучения, определяющие образовательное пространство как инструмент влияния на образовательный процесс и развитие учащихся. Основная идея заключается в том, что образовательное пространство, организованное определенным образом, помогает снять поведенческие ограничения и обеспечить свободу выбора средств обучения, возможностей для самовыражения и творческой деятельности, развития самостоятельности учащихся.

Среди них мы выделяем: подход к проектированию пространственно-предметного компонента модели развивающей образовательной среды В. А. Ясвина (2019), подход к проектированию образовательного пространства на основе теории множественного интеллекта Говарда Гарднера (2007), подход к организации пространственного окружения ребенка Марии Монтессори (2005), концепцию образовательного пространства как «третьего учителя» в реджио-педагогике (Edwards, Gandini, Forman, 2017), подход к организации образовательного пространства в концепции активного обучения (Вербицкий, 1991; Луминен, Римпеля, Тарвайнен, 2018), подход к проектированию образовательного пространства для развития навыков «4К» (Kivunja, 2014; Creativity \& innovation..., 2016; Soulé, Warrick, 2015; Thomas, Brown, 2011).

Для того чтобы выделить условия создания персонализированного образовательного пространства, мы провели сравнительный анализ вышеперечисленных подходов по следующим параметрам:

- роль образовательного пространства в процессе обучения;

- принципы проектирования образовательного пространства;

- наполнение образовательного пространства;

- влияние образовательного пространства на процесс обучения.

По параметру «роль образовательного пространства в процессе обучения» анализируемые педагогические подходы связывает понимание образовательного пространства как места, в котором создаются разнообразные возможности, побуждающие учащихся и педагогов к активности и творческой деятельности в целях личностного развития ребенка с учетом его предпочтений и способностей. При этом в каждом подходе есть свои особенности. В модели развивающей образовательной среды В. А. Ясвина делается акцент на создании развивающих стимулов для раскрытия потенциала учащихся. В теории множественного интеллекта Говарда Гарднера заостряется внимание на организации условий для расширения способов объяснения материала в соответствии с различными когнитивными стилями обучения. В системе Марии Монтессори образовательное пространство направлено на развитие самостоятельности ребенка и его практических навыков. В концепции активного обучения - стимулирует вовлеченность и субъектную активность учащихся. В подходе к развитию навыков «4К» на первый план выдвигается необходимость создания оптимальных условий для развития критического мышления, креативности, коммуникации и кооперации.

Следующий параметр - принципы проектирования образовательного пространства. Здесь анализируемые подходы объединяет идея создания свободного доступа к ресурсам образовательного пространства на основе принципов открытости, гибкости, функциональности и эргономичности. Особенностью модели развивающей образовательной среды В. А. Ясвина являются символизм, индивидуализированность и аутентичность 
образовательного пространства. В теории множественного интеллекта Говарда Гарднера подчеркивается важность деления на тематические зоны по типам интеллекта. В антропологической концепции Марии Монтессори отмечается умеренная насыщенность образовательного пространства и его соответствие возрастным, сензитивным и психофизическим особенностям ребенка. В концепции активного обучения - многофункциональность общественных зон и комфортные акустические условия. В подходе к развитию навыков «4К» выделяется обеспечение возможностями для ведения открытого диалога.

По третьему параметру - «наполнение образовательного пространства» - во всех анализируемых подходах отмечается значимость наличия в образовательном пространстве различных видов стимулов и элементов для взаимодействия, возможности свободной трансформации учебных и общественных помещений под разные учебные задачи; наличия зоны для уединения; зоны групповой работы; возможности для самовыражения и творческой деятельности по выбору. Отличительными особенностями модели В. А. Ясвина являются важность в образовательном пространстве символических элементов, зон для физической активности и возможность изменять пространство, дополняя его личностно значимыми предметами. В теории множественного интеллекта Говарда Гарднера выделяется необходимость в специально оборудованных мастерских и лабораториях, а также в отдельных кабинетах с возможностью комфортного проведения лекций, работы с литературой, видео- и аудиоматериалами. В подходе к организации образовательного пространства Марии Монтессори стоит отметить зонирование по возрастным группам: 1-3 года и 3-7 лет, - а также важность использования натуральных материалов преимущественно светлых оттенков для оформления стен, пола, мебели и живых растений в учебных комнатах. В концепции активного обучения важны просторные помещения с мобильными и стеклянными перегородками и интерьерные акустические решения. Отличительной особенностью подхода к развитию навыков «4К» является наличие в образовательном пространстве маркерных и грифельных стен, а также магнитных и пробковых поверхностей и зон для взаимодействия.

Сравнение подходов по параметру «влияние образовательного пространства на процесс обучения» позволило выявить ряд повторяющихся связей:

- свободный доступ к ресурсам образовательного пространства и множество элементов для взаимодействия обеспечивают учащимся свободу выбора и проявление инициативности и самостоятельности;

- наполненность образовательного пространства различными видами стимулов способствует повышению познавательной активности учащихся и раскрытию их личностного потенциала;

многофункциональность и возможность свободной трансформации учебных и общественных помещений дают педагогам множество инструментов для расширения их методов преподавания и способствуют более эффективному усвоению изучаемого материала учащимися;

- наличие множества зон для различных целей обучения вдохновляет и дает возможность для свободного выбора деятельности на основе личных предпочтений и интересов;

- возможности для самовыражения и творческой деятельности по выбору усиливают мотивацию и творческую активность учащихся;

возможность уединиться дает чувство безопасности, как физической, так и эмоциональной, и, кроме того, позволяет учащимся самостоятельно работать над заданиями, требующими концентрации внимания, развивая свою самостоятельность и самоконтроль;

- наличие зон для групповой работы позволяет практиковать навыки коммуникации и сотрудничества, стимулирует к творческой совместной деятельности.

Также стоит отметить и отличительные особенности в каждом из подходов к проектированию персонализированного образовательного пространства. В модели В. А. Ясвина символические элементы важны для создания дополнительных возможностей эстетического, познавательного и этического развития, опосредованно влияют на сплоченность и сознательность учащихся, создают чувство эмоционального комфорта и принадлежности. Зоны для физической активности необходимы, поскольку обеспечивают удовлетворение потребности в высокой двигательной активности школьников с учетом специфики их восприятия мира. Возможность изменять пространство, дополняя его личностно значимыми предметами, позволяет как учащемуся, так и педагогу персонализировать физическое окружение, тем самым присваивая пространство, благодаря чему образовательное пространство воспринимается как безопасное, что способствует повышению субъектной активности и раскрытию потенциала личности.

В теории множественного интеллекта Говарда Гарднера в тематических зонах и специально оборудованных мастерских и лабораториях учащиеся полностью погружаются в конкретную деятельность по выбранному направлению, что способствует более эффективному усвоению изучаемого материала. А в отдельных кабинетах с возможностью комфортного проведения лекций, работы с литературой, видео- и аудиоматериалами учатся в традиционных форматах.

В подходе к организации образовательного пространства Марии Монтессори использование натуральных материалов преимущественно светлых оттенков для оформления стен, пола, мебели, а также живых растений в учебных комнатах необходимо для создания символической связи с природой и сохранения умеренной насыщенности в образовательном пространстве для концентрации внимания учащихся. Зоны для детей 1-3 лет служат средством для развития крупной и мелкой моторики, речи, чувственного восприятия, понимания причинноследственных связей, навыков самообслуживания и творчества. А зоны для детей 3-7 лет - для развития речи, социального поведения, чувственного опыта и физического развития, для овладения новыми знаниями по математике и окружающему миру.

В концепции активного обучения большие по площади помещения позволяют организовывать работу в группах различной численности, а благодаря мобильным и стеклянным перегородкам можно обособить 
часть пространства, при этом сохранив визуальную связь, что способствует созданию атмосферы познавательной деятельности повсюду. Так усиливается учебная мотивация. Кроме того, стеклянные перегородки служат средством контроля над негативными эмоциональными проявлениями участников образовательного процесса. А интерьерные акустические решения минимизируют уровень шума в открытых пространствах, что позволяет учащимся заниматься, не мешая друг другу.

В подходе к развитию навыков «4К» маркерные и грифельные стены позволяют использовать методы визуализации проблемного поля, чтобы наглядно увидеть взаимосвязи, критически осмыслить проблемные точки и найти оптимальные пути решения. Зоны для взаимодействия обеспечивают возможность открытого диалога, в ходе которого учащиеся логически рассуждают, учатся аргументировать свою позицию, анализировать и оценивать информацию.

В результате сравнительного анализа педагогических подходов мы приходим к выводу, что для создания персонализированного образовательного пространства, в котором возникают разнообразные возможности, побуждающие учащихся и педагогов к активности и творческой деятельности в целях личностного развития ребенка с учетом его предпочтений и способностей, необходимо обеспечить свободный доступ к ресурсам образовательного пространства на основе принципов открытости, гибкости, функциональности и эргономичности. При этом важно, чтобы образовательное пространство было наполнено различными видами стимулов и элементов для взаимодействия с возможностью свободной трансформации учебных и общественных помещений под разные учебные задачи. Также важно создать в персонализированном образовательном пространстве возможности для самовыражения и творческой деятельности по выбору, групповой работы и уединения.

\section{Влияние условий проектирования образовательного пространства на персонализацию процесса обучения}

Сравнительный анализ рассмотренных подходов позволил нам сформировать представление о педагогических и эргономических условиях проектирования персонализированного образовательного пространства, среди которых мы выделяем:

«- разнообразие и доступность материалов, оборудования, видов активности;

- снятие поведенческих ограничений и свобода выбора деятельности;

- возможность взаимодействия с пространством, реализация учащимися пространственного и предметного выбора, изменение своего пространственного окружения;

- возможность для самовыражения и творческой деятельности;

- возможность группового взаимодействия и неформального общения;

- возможность уединения для самостоятельной работы и спокойного отдыха» (Арно, 2018, с. 88);

- соответствие возрастным, психофизиологическим и индивидуальным характеристикам учащихся.

Целесообразно рассмотреть влияние на образовательный процесс каждого условия в отдельности.

Разнообразие и доступность материалов, оборудования, видов активности создают для учащихся развивающие возможности на основе их интересов и предпочтений и являются средством индивидуализации образовательного процесса на основе личностных различий. Это дает учащимся возможность не только развивать свои сильные стороны, но и в комфортной обстановке пробовать новые способы изучения материала и новые виды деятельности, что способствует раскрытию потенциальных талантов и способностей. Чем разнообразнее возможности образовательного пространства, тем активнее учащиеся стремятся овладеть новыми знаниями и видами деятельности. Нам близка позиция В. А. Ясвина (2019), что образовательное пространство необходимо наполнять различными видами стимулов, способствующими познавательной активности учащихся. Среди них: сенсорные стимулы; стимулы, побуждающие к практической деятельности и развивающие когнитивные способности; стимулы, активизирующие психологические механизмы личностного развития, а также личностнозначимые стимулы (с. 63-65). Это подтверждается и в теории множественного интеллекта Говарда Гарднера (2007), где насыщенное образовательное пространство рассматривается как ресурс, способствующий возникновению разнообразных познавательных возможностей, соответствующих интеллектуальному потенциалу учащихся. Разнообразие и доступность материалов, оборудования, видов активности позволяют педагогам находить новые эффективные способы использования возможностей пространства в образовательном процессе и повышают вовлеченность педагогов в цели развития учащихся. Благодаря разнообразным возможностям образовательного пространства педагоги могут расширять свой арсенал подходов к объяснению изучаемого материала, что способствует его более эффективному усвоению у учащихся.

Снятие поведенческих ограничений и свобода выбора деятельности служат средством повышения субъектной активности учащегося в процессе обучения и возникновения новых форм мотивации. Это позволяет снять психологические зажимы, как у учащихся, так и у педагогов, и побудить их к творческой деятельности. Возможность свободного перемещения в образовательном пространстве в зависимости от собственных интересов «способствует проявлению их любопытства и стремления к участию в наблюдаемом процессе или вдохновению на создание собственного проекта» (Подымова, Арно, 2019, с. 362). С позиции физиологии смена рабочего положения способствует активизации мышечной деятельности учащихся, что в свою очередь поддерживает их в бодром состоянии в течение дня, влияет на способность усваивать информацию и творчески подходить к решению учебных задач (Blake, Benden, Wendel, 2012). Возможность проявлять спонтанную активность в образовательном пространстве и развиваться в собственном темпе выделяется как важный аспект в антропологической концепции развития ребенка Марии Монтессори, где подчёркивается важность свободы выбора для саморазвития учащегося и становления его самостоятельности. 
Возможность взаимодействия с пространством, реализация учащимися пространственного и предметного выбора, изменение своего пространственного окружения. Данная возможность стимулирует учащихся к самостоятельному трансформированию образовательного пространства в зависимости от их интересов и потребностей. При постоянном осуществлении пространственного и предметного выбора и наблюдения за другими у участников образовательного процесса возрастает желание быть активными, пробовать новое и инициировать преобразования. Так, учащиеся «могут самостоятельно выбирать наиболее комфортное для себя место, вид деятельности, с помощью мобильной и легкой мебели самостоятельно менять пространство под свои потребности и интересы» (Подымова, Арно, 2019, с. 361). Они могут заниматься как в группах, так и индивидуально, организовывать дебаты, дискуссии, обсуждения проектов, практиковаться в творческой деятельности и нестандартно подходить к решению учебных задач. Такое образовательное пространство вдохновляет и дает возможность для свободного выбора, усиливает мотивацию, как учащихся, так и преподавателей, развивает творческую активность учащихся и их навыки коммуникации и сотрудничества, стимулирует к творческой совместной работе. Меняя своё пространственное окружение и наблюдая результаты своих трансформаций, учащиеся развивают самостоятельность. Они сами инициируют преобразования, в ходе которых учатся ставить цели, планировать свою деятельность, в том числе в группе, видеть результат и нести за него ответственность. Также это дает дополнительное преимущество для педагогов в части организации группового взаимодействия. Можно быстро сменить формат работы учащихся в зависимости от образовательных целей.

Возможность для самовыражения и творческой деятельности. Такая возможность, созданная в образовательном пространстве, способствует раскрытию творческого потенциала учащихся и реализации их творческих возможностей на основе личных интересов и предпочтений. Возможность самовыражения в образовательном пространстве способствует раскрытию креативных способностей учащихся и стимулирует их инициативность и активность в практической реализации своих замыслов, позволяя осознать свою значимость и повышая уверенность в собственных силах.

Возможность группового взаимодействия и неформального общения позволяет организовывать групповую работу в различных форматах, что способствует развитию коммуникативных навыков, навыков кооперации и сотрудничества, критического мышления, самопознания, стимулирует познавательную активность. «Участвуя в разговорах, слушая взрослых и сверстников, наблюдая, как люди общаются, и, выступая самостоятельно, дети учатся коммуникации» (Подымова, Арно, 2019, с. 361). Групповое взаимодействие, как в учебных помещениях, так и в общественных, позволяет им практиковать свои коммуникативные навыки повсеместно. Говард Гарднер (2007) подчеркивает, что в групповом взаимодействии создаются возможности для развития не только вербально-лингвистического и межличностного типов интеллекта, но и для сотрудничества и дружбы. В совместной деятельности учащиеся учатся осознавать эмоции и идеи других, уважать и ценить партнеров, признавать их точку зрения, идти на компромиссы. Логически рассуждая и аргументируя свою позицию, учащиеся развивают критическое мышление, учатся выделять проблемы и творчески подходить к их решению.

Возможность уединения для самостоятельной работы и спокойного отдыха мы выделяем как условие создания персонализированного пространства, поскольку это является важным аспектом для формирования у участников образовательного процесса чувства безопасности, как физической, так и эмоциональной. Кроме того, данная возможность способствует развитию рефлексии, ощущения собственной значимости и уверенности в себе, позитивного отношения к образовательной среде в целом. Учащиеся могут сосредоточиться над заданием и самостоятельно позаниматься в спокойной обстановке, что развивает навыки самостоятельной работы и самоконтроля. Это является одним из условий, обеспечивающих достижение индивидуальных образовательных целей.

Соответствие возможностей образовательного пространства возрастным, психофизиологическим и индивидуальным характеристикам учащихся обеспечивает наиболее полную реализацию их интеллектуальных способностей и раскрытие природного потенциала с учетом возрастных изменений и когнитивных стилей обучения, способствует восприятию учащимися образовательного пространства как психологически комфортного и безопасного, что положительно влияет на эмоциональную устойчивость и познавательную мотивацию детей, повышает способности к саморегуляции и укрепляет межличностные отношения. В таком образовательном пространстве учащиеся могут проявлять субъектную активность, основываясь исключительно на своих собственных интересах и возможностях, выбирая темп и уровень сложности, что помогает развитию их познавательной самостоятельности.

Таким образом, соответствие возможностей образовательного пространства возрастным, психофизиологическим и индивидуальным характеристикам учащихся будет способствовать восприятию учащимися образовательного пространства как психологически комфортного и безопасного, что положительно повлияет на эмоциональную устойчивость и познавательную мотивацию детей, будет способствовать развитию способности к саморегуляции и укреплению межличностных отношений.

\section{Заключение}

Таким образом, мы приходим к следующим выводам. Выделенные условия: разнообразие и доступность материалов, оборудования, видов активности; снятие поведенческих ограничений и свобода выбора деятельности; возможность взаимодействия с пространством, реализация учащимися пространственного и предметного выбора, изменение своего пространственного окружения; возможность для самовыражения и творческой деятельности; возможность группового взаимодействия и неформального общения; возможность уединения для самостоятельной работы и спокойного отдыха; соответствие возрастным, психофизиологическим 
и индивидуальным характеристикам учащихся, - позволяют спроектировать персонализированное образовательное пространство, в котором создаются возможности для проявления субъектной активности учащихся и свободного выбора деятельности в соответствии с их стремлениями в саморазвитии на основе индивидуальных интересов, способностей и значимых образовательных целей.

Персонализированное образовательное пространство способствует взаимодействию всех участников образовательного процесса, усиливает мотивацию, как учащихся, так и педагогов, развивает творческую активность учащихся и их навыки коммуникации и сотрудничества, стимулирует к творческой совместной работе. Созданные в персонализированном образовательном пространстве возможности способствуют развитию рефлексии учащихся, уверенности в себе, навыков самостоятельной работы и самоконтроля.

Перспективы дальнейшего исследования проблемы мы видим в изучении и разработке практических и методологических основ использования возможностей персонализированного образовательного пространства для повышения эффективности применения технологий персонализации обучения в целях проявления и развития потенциала учащихся, повышения их субъектной активности и вовлеченности в учебный процесс, развития навыков сотрудничества, коммуникации, креативности, критического мышления, рефлексии и самостоятельности.

\section{Источники | References}

1. Арно А. О. Проект образовательного пространства начальной школы // Нижегородское образование. 2018 . № 1.

2. Вербицкий А. А. Активное обучение в высшей школе: контекстный подход. М., 1991.

3. Гарднер Г. Структура разума: теория множественного интеллекта. М.: ИД «Вильямс», 2007.

4. Грачев В. В. Персонализация образования как ответ на глобальные вызовы современности // Акмеология. 2005. № 2 (14).

5. Кириллов П. Н., Корякина Н. И. Школа возможностей: индивидуальные траектории развития // Образовательная политика. 2019. № 3 (79). URL: https://edpolicy.ru/school-of-opportunity

6. Луминен Х., Римпеля М., Тарвайнен Э. Cookbook 2.0. Рецепты современного дизайна образовательной среды. Тампере: Finnish Education Group, 2018.

7. Монтессори М. Дом ребёнка. Метод научной педагогики. М.: АСТ; Астрель, 2005.

8. Образование преображает жизнь людей. OOH, 2017. URL: https://unesdoc.unesco.org/ark:/48223/pf0000247234 rus.locale $=r u$

9. Подымова Л. С., Арно А. О. Возможности образовательного пространства для развития навыков «4к»: критического мышления, коммуникации, креативности, кооперации // Человеческий капитал. 2019. № S12-2 (132).

10. Ясвин В. А. Школьная среда как предмет измерения: экспертиза, проектирование, управление. М.: Народное образование, 2019.

11. Blake J. J., Benden M. E., Wendel M. L. Using stand/sit workstations in classrooms: Lessons learned from a pilot study in Texas // Journal of Public Health Management and Practice. 2012. Vol. 18. Issue 5. DOI: 10.1097/PHH. Ob013e3182215048

12. Creativity \& innovation: Theory, research, and practice / ed. by J. A. Plucker. Prufrock Press, 2016.

13. Edwards C., Gandini L., Forman G. I cento linguaggi dei bambini. Edizioni Junior, 2017.

14. Kivunja C. Do You Want Your Students to Be Job-ready with 21st Century Skills? Change Pedagogies: A Paradigm Shift from Vygotskyian Social Constructivism to Critical Thinking, Problem Solving and Siemens' Digital Connectivism // International Journal of Higher Education. 2014. Vol. 3. № 3. URL: http://dx.doi.org/10.5430/ijhe.v3n3p81

15. Soulé H., Warrick T. Defining 21st century readiness for all students: What we know and how to get there // Psychology of Aesthetics, Creativity, and the Arts. 2015. Vol. 9. Issue 2. DOI: 10.1037/aca0000017

16. Thomas D., Brown J. S. A New Culture of Learning: Cultivating the Imagination for a World of Constant Change. CreateSpace Independent Publishing Platform, 2011.

\section{Информация об авторах | Author information}

RU Арно Анна Олеговна ${ }^{1}$

${ }^{1}$ Московский педагогический государственный университет

EN Arno Anna Olegovna ${ }^{1}$

${ }^{1}$ Moscow Pedagogical State University

${ }^{1}$ anyarno@gmail.com

\section{Информация о статье | About this article}

Дата поступления рукописи (received): 03.08.2021; опубликовано (published): 29.10.2021.

Ключевые слова (keywords): педагогические условия; эргономические условия; проектирование; персонализированное образовательное пространство; pedagogical conditions; ergonomic conditions; design; personalized educational space. 